\title{
First report of Gilbertella persicaria as the cause of soft rot of fruit of Syzygium cumini
}

\author{
Danilo B. Pinho • Olinto L. Pereira • Dartanha J. Soares
}

Received: 5 June 2014 / Accepted: 23 July 2014 / Published online: 1 August 2014

(C) Australasian Plant Pathology Society Inc. 2014

\begin{abstract}
A zygomycetous fungus causing fruit soft rot was found on Sygyzium cumini in Northeast Brazil. Based on morphological and phylogenetic analyses, the fungus was identified as Gilbertella persicaria. This is the first report of this fungus causing the decay of $S$. cumini fruit worldwide.
\end{abstract}

Keywords Choanephoraceae · Fruit decay · Mucorales · Myrtaceae $\cdot$ Zygomycetes

Fruits of Syzygium cumini (L.) Skeels (Myrtaceae) that showed soft rot symptoms caused by Mucorales (Zygomycetes) (Fig. 1a) were collected in the wet season of 2010 from Paraíba State (northeast Brazil). Syzygium cumini, known as jambolan or black plum, was naturalized in Brazil and has no commercial interest, despite its use in folk medicine and evidence of its pharmacological properties (Ayyanar and Subash-Babu 2012).

Soft roted fruits were examined under a stereo-microscope, which confirmed the presence of a Mucor-like fungus. The fungus was then isolated on potato dextrose-agar (PDA), by direct transfer of a spore mass using a sterile needle and the culture derived was deposited in the Culture Collection of the Universidade Federal de Viçosa (accession number COAD 1728) and also in the Culture Collection of Phytopathogenic Microorganisms of the Embrapa Algodão (accession number CCMF-CNPA 0627).

D. B. Pinho • O. L. Pereira

Departamento de Fitopatologia, Universidade Federal de Viçosa,

36570-900 Viçosa, MG, Brazil

\section{J. Soares $(\bowtie)$}

Embrapa Algodão, Rua Oswaldo Cruz, 1143, Centenário, 58428-095 Campina Grande, PB, Brazil

e-mail: dartjs@yahoo.com.br
Identification of the fungus was based on its morphological characteristics, and the identity was later confirmed using molecular methods. Fungal structures obtained from the culture plates were mounted in lactic acid or water on microscope slides and were examined under a Leica DM2500 microscope equipped with DIC lenses. The genomic DNA was extracted from pure cultures grown on PDA using a Wizard ${ }^{\circledR}$ Genomic DNA Purification Kit (Promega Corporation, WI, U.S.A.), as described in Pinho et al. (2012). The target regions of the internal transcribed spacer (ITS) and the $28 \mathrm{~S}$ rDNA large subunit (LSU) were amplified using ITS1/ITS4 and LR0R/ LR5 primers, respectively (Vilgalys and Hester 1990; White et al. 1990). The sequences were edited using BioEdit software (Hall 2012). A BLAST search was performed to check for similarity with other sequences. The sequences used in the study were selected from a phylogenetic tree provided in Walther et al. (2013) and were aligned using the multiple sequence alignment program MUSCLE $^{\circledR}$ (Edgar 2004) in MEGA v. 5 software (Tamura et al. 2011). Bayesian inference concatenated (BI) analyses were performed using the ITS dataset and the resulting alignment and tree were deposited in TreeBASE (http://www.treebase.org/) as accession number S15860. The best nucleotide substitution model selected according to the Akaike information criterion (AIC) was $\mathrm{HKY}+\mathrm{G}$ for ITS. The Bayesian analysis was performed in the CIPRES Science Gateway (Miller et al. 2010) using MrBayes on XSEDE, and the tree was rooted to Hyphomucor assamensis CBS415.77.

The pathogenicity of the fungus was tested on $S$. cumini fruits that were surface sterilized and inoculated by touching the fungal spore mass, growth on PDA, with a sterile needle, which was then used to puncture the fruits. After inoculation, the fruits were maintained in a dew chamber in daylight on the bench $\left(\right.$ at $\left.\sim 25^{\circ} \mathrm{C}\right)$. 
When grown on PDA at $25^{\circ} \mathrm{C}$, the fungus initially produced a white colony, which covered the entire $90 \mathrm{~mm}$ diam. Petri dish within 3 days, and became darker with age. A darker zone formed between colonies on the Petri dish used for culture isolation revealed the presence of the sexual structures of the fungus. Zygospores globose to subglobose, compressed
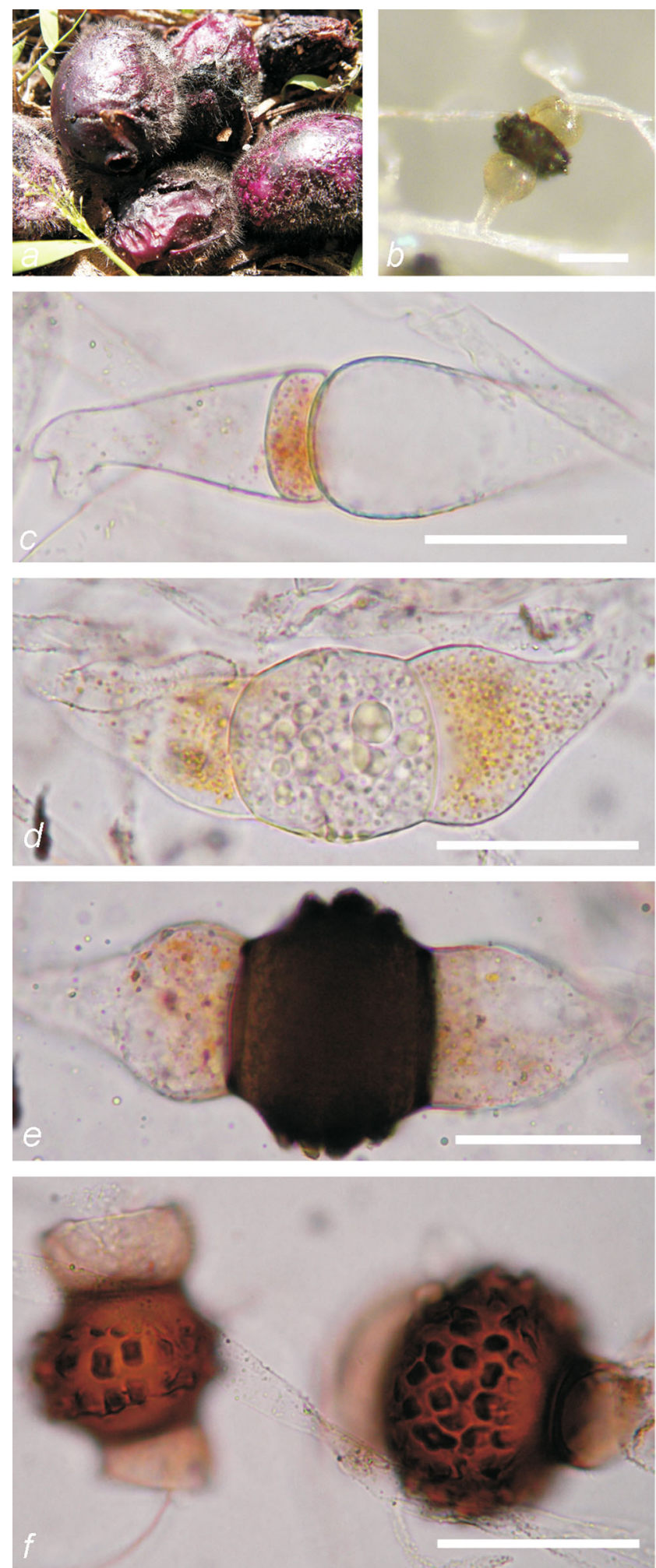
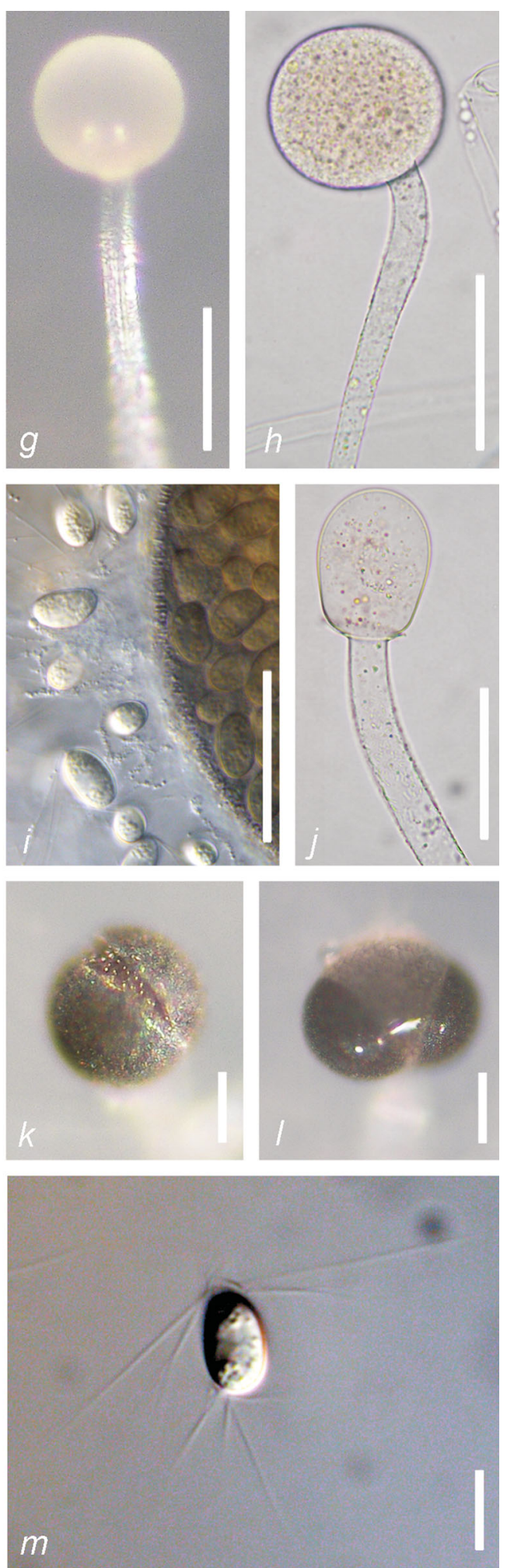

showing spines (i). Columellae (j). Wall suturing in two equal halves $(\mathbf{k}-\mathbf{l})$. Sporangiospore with appendages $(\mathbf{m})$. Scale bars $=50 \mu \mathrm{m}$, except

in $m$ in which the $b a r=10 \mu \mathrm{m}$
Fig. 1 Gilbertella persicaria. Typical image of the affected fruit of Syzygium cumini (a). Zygospore formation sequence (b-f). Immature sporophores $(\mathbf{g}-\mathbf{h})$. Higher magnification view of the sporangial wall 
Fig. 2 Phylogenetic tree inferred from the Bayesian analysis based on the ITS sequences of the Gilbertella persicaria and related taxa. The Bayesian posterior probability values are indicated at the nodes. The tree was rooted to Hyphomucor assamensis. The specimen used in this study is highlighted in bold

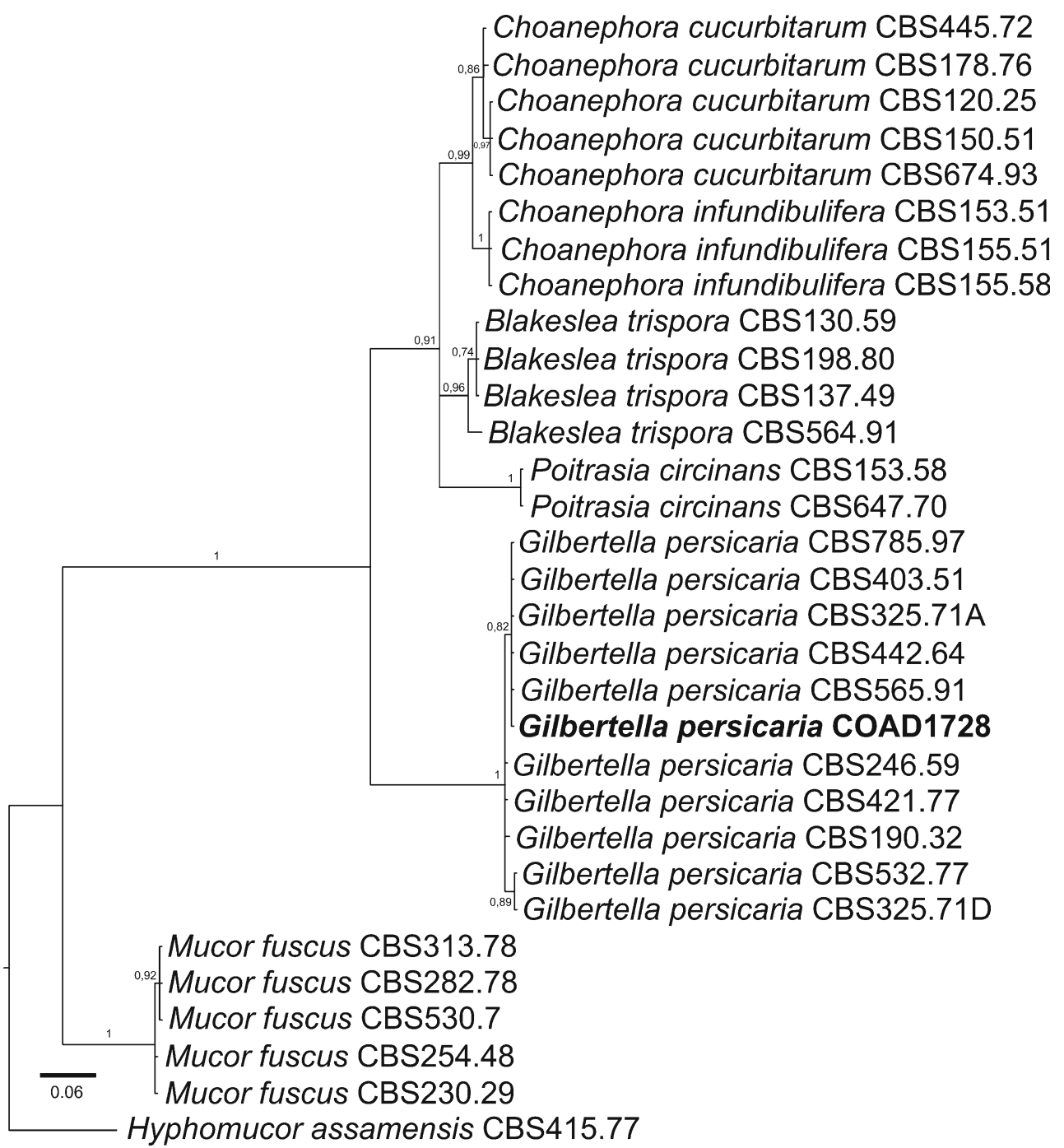

between suspensors, with coarse projections (Fig. 1b-f). Sporophores hyaline, becoming pale brown with age, simple, sometimes branched, erect, curved below the sporangium. Sporangia spherical, initially white-yellowish, turning light to dark brown or black when mature (Fig. 1g-h); wall persistent, covered with spines (Fig. 1i), separating at maturity into two equal halves (Fig. 1k-1); columellae obvoid to globose, with a distinct basal collar (Fig. 1j). Sporangiospores variable in shape, mainly ellipsoid, hyaline, smooth, one-celled, with hyaline filiform appendages at both ends (Fig. $1 \mathrm{~m}$ ).

Based on the above-mentioned characteristics, the fungus was identified as a member of the genus Gilbertella Hesseltine. At least three names are recognized within Gilbertella, viz. G. persicaria (E.D. Eddy) Hesselt., G. persicaria var. indica B.S. Mehrotra \& M.D. Mehrotra and $G$. hainanensis J.Y. Cheng \& F.M. Hu, with G. persicaria being the type species (Hesseltine 1960); however, in a recent treatise concerning Mucorales, Walther et al. (2013) regarded those names as synonyms of $G$. persicaria, and the genus is now considered monotypic.
The Bayesian analysis confirmed that the fungus found on S. cumini belongs to the genus Gilbertella and can be grouped in the same clade as other taxa of the family Choanephoraceae (data not shown), according to the new classification adopted by Hoffmann et al. (2013). The BLAST search using the sequences ITS (KJ815093) and LSU (KJ815094) regions revealed $99 \%$ identity with the ITS (Accession No. NR_111692) and LSU (Accession No. JN939197) sequences from the type material (strain CBS 190.32) of G. persicaria. Morphological examination and Bayesian analysis (Fig. 2) revealed that the fungus found on $S$. cumini is $G$. persicaria.

The first symptoms appeared between 16 and $24 \mathrm{~h}$ after inoculation in the form of a small depression of the fruit pulp at the point of inoculation. The fungus sporulated on fruits in less than $36 \mathrm{~h}$, whereas the controls (non-inoculated fruits) remained intact (Fig. 3).

Gilbertella persicaria is known mainly as a postharvest rot fungus, but is frequently isolated from soil and dung 

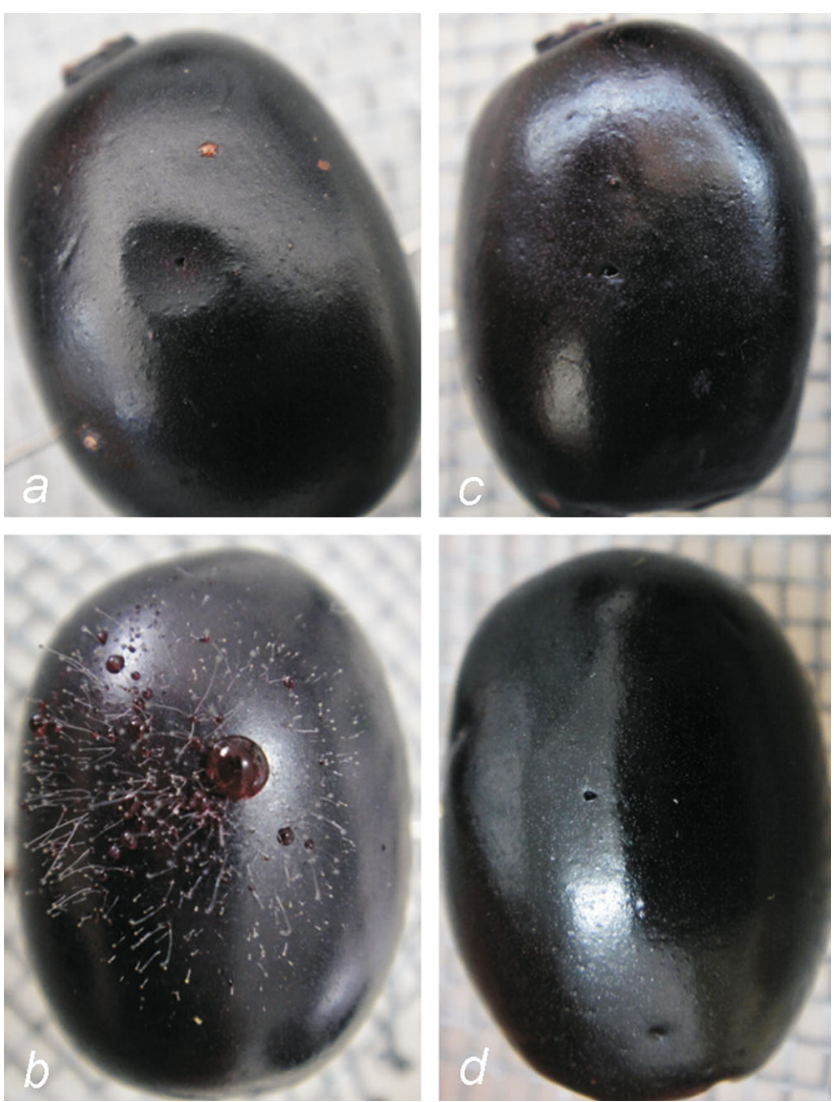

Fig. 3 Pathogenicity test of Gilbertella persicaria on Syzygium cumini fruits. Inoculated fruit $18 \mathrm{~h}$ after inoculation, showing the slight depression in the pulp (a) and at $36 \mathrm{~h}$, showing the sporulating fungus (b). Noninoculated fruit at $18 \mathrm{~h}(\mathbf{c})$ and $36 \mathrm{~h}(\mathbf{d})$, showing its intact pulp

(Hesseltine 1960; Mehrotra 1964; Benny 1991; Ginting et al. 1996; Santiago and Cavalcanti 2007; Guo et al. 2012). In Brazil, this fungus was first reported from soil samples in Rio de Janerio State, by Hesseltine (1960). It was subsequently reported from tapir, donkey and elk dung, in Pernambuco State, by Santiago and Cavalcanti (2007) who mistakenly regarded it as the first report in Brazil.

To our knowledge, this is the first report of G. persicaria associated with the fruit soft rot of $S$. cumini worldwide.

Acknowledgments The authors would like to thank the Coordenação de Aperfeiçoamento de Pessoal de Nível Superior (CAPES), the Conselho Nacional de Desenvolvimento Científico e Tecnológico $(\mathrm{CNPq})$ and the Fundação de Amparo à Pesquisa do Estado de Minas Gerais (FAPEMIG) for financial support.

\section{References}

Ayyanar M, Subash-Babu P (2012) Syzygium cumini (L.) skeels: a review of its phytochemical constituents and traditional uses. Asian Pac J Trop Biomed 2:240-246

Benny GL (1991) Gilbertellaceae, a new family of the Mucorales (Zygomycetes). Mycologia 83:150-157

Edgar RC (2004) MUSCLE: multiple sequence alignment with high accuracy and high throughput. Nucleic Acids Res 32: 1792-1797

Ginting C, Zehr EI, Westcott SW III (1996) Inoculum sources and characterization of isolates of Gilbertella persicaria from peach fruit in South Carolina. Plant Dis 80:1129-1134

Guo LW, Wu YX, Mao ZC, Ho HH, He YQ (2012) Storage rot of dragon fruit caused by Gilbertella persicaria. Plant Dis 96:1826

Hall T (2012) BioEdit v7.0.9: Biological sequence alignment editor for Win $95 / 98 / 2 \mathrm{~K} / \mathrm{XP} / 7$. Available at http://www.mbio.ncsu.edu/ bioedit/bioedit.html Acessed 15 July 2012

Hesseltine CW (1960) Gilbertella gen. nov. (Mucorales). Bull Torrey Bot Club 87:21-30

Hoffmann K, Pawlowska J, Walther G, Wrzosek M, Hoog GS, Benny GL, Kirk PM, Voigt K (2013) The family structure of the Mucorales: a synoptic revision based on comprehensive multigene-genealogies. Persoonia 30:57-76

Mehrotra MD (1964) Fruit rot of tomato caused by Gilbertella persicaria. Sydowia 17:17-19

Miller MA, Pfeiffer W, Schwartz T (2010) Creating the CIPRES Science Gateway for inference of large phylogenetic trees. In: Proceedings of the Gateway Computing Environments Workshop (GCE). New Orleans LA, USA. pp. 1-8

Pinho DB, Firmino AL, Pereira OL, Ferreira Junior WG (2012) An efficient protocol for DNA extraction from Meliolales and the description of Meliola centellae sp. nov. Mycotaxon 122: 333-345

Santiago ALCMA, Cavalcanti MAQ (2007) Gilbertella persicaria (Mucorales): a new record from Brazil. Mycotaxon 102:333-337

Tamura K, Peterson D, Peterson N, Stecher G, Nei M, Kumar S (2011) MEGA5: molecular evolutionary genetics analysis using maximum likelihood, evolutionary distance, and maximum parsimony methods. Mol Biol Evol 28:2731-2739

Vilgalys R, Hester M (1990) Rapid genetic identifcation and mapping of enzymatically amplifed ribosomal DNA from several Cryptococcus species. J Bacteriol 172:4239-4246

Walther G, Pawłowska J, Alastruey-Izquierdo A, Wrzosek M, RodriguezTudela JL, Dolatabadi S, Chakrabarti A, de Hoog GS (2013) DNA barcoding in Mucorales: an inventory of biodiversity. Persoonia 30: $11-47$

White TJ, Bruns T, Lee S, Taylor J (1990) Amplifcation and direct sequencing of fungal ribosomal RNA genes for phylogenetics. In: Innis MA, Gelfand DH, Sninsky JJ, White TJ (eds) PCR protocols: a guide to methods and applications. Academic, San Diego, pp 315322 